\title{
PAPER
}

\section{A preliminary declaration of sustainability ethics: making peace with the ultimate bioexecutioner}

\author{
John Cairns, Jr.* \\ Department of Biology, Virginia Polytechnic Institute and State University, Blacksburg, Virginia 24061, USA
}

\begin{abstract}
Sustainability is a utopian vision that requires living harmoniously with nature, which will exact harsh penalties on species that exceed Earth's carrying capacity and violate nature's laws. To make this vision a reality, humankind needs a global ethical consensus on sustainable use of the planet-sustainability ethics. Sustainability ethics has the goal of developing a sustainable, mutualistic relationship between humankind and the interdependent web of life that serves as Earth's ecological life support system. The quest for sustainable use of the planet is a value judgment that has more than one component. Arguably, the most important is increased attention to and compassion for posterity's quality of life, in short, leaving a habitable planet for future generations. This requires leaving natural capital and the ecosystem services it provides undiminished at the least and increased at best. Although material possessions can be left to direct descendants, protecting the planet's ecological life support system must not only be for all of humankind's descendants but those of the 30+ million other species with which we share the planet. This is difficult because the recipients are distant (as individuals) both temporally and spatially. Therefore, this quest will not be realized until an agreement emerges on the values and attitudes necessary to make sustainability a reality. Science can then develop the standards and criteria necessary to reach this goal. In view of present unsustainable practices, a basic ethical consensus is necessary to develop sustainable practices.
\end{abstract}

KEY WORDS: Sustainability · Sustainability ethics · Eco-ethics · Social contract · Ecocentric viewpoint

Resale or republication not permitted without written consent of the publisher

In the end, however, success or failure will come down to an ethical decision, one on which those now living will be defined and judged for all generations to come. $\quad$ E. O. Wilson, 2002

\section{ECO-ETHICS AND SUSTAINABILITY ETHICS}

Important similarities are present in the concepts of eco-ethics (Kinne 2003) and sustainability ethics. Both focus intently upon the ethical relationship between humankind and natural systems. Both deplore the folly of humankind's present unsustainable course, which includes exhausting the planet's nonrenewable resources such as fossil fuels, water, and minerals. Both deplore the over-harvesting of renewable resources such as oceanic fisheries and old growth forests. Both agree that global environmental quality is being degraded by automobile emissions, pesticides, nuclear wastes, greenhouse gases, chlorofluorocarbons, and the like, which produce such environmental responses as biotic impoverishment (i.e. species extinction), global warming, and acid rain. Both are deeply concerned about the exponentially growing human population; increased per capita affluence, as measured by consumption of material goods; and the increasing disparity in per capita distribution of the planet's resources.

Sustainability ethics is a consilience (literally 'leaping together') of econ-ethics and eco-ethics. As Kinne 
notes, both concepts are required for sustainability. ${ }^{1}$ Arguably, the major difference between eco-ethics and sustainability ethics is that the latter envisions that Homo sapiens will exist on the planet indefinitely. Since species come and go in the evolutionary process, one might question whether the infinite existence of humans is an ethical position. A related difference is that eco-ethics is ecocentric while sustainability ethics is both homocentric and ecocentric. Sustainability ethics is defensible if one assumes humankind and natural systems are co-evolving in a mutually beneficial way. The concept is not ethically defensible if one assumes sustainable use of the planet has the primary goal of manipulating natural systems so that they are always optimally beneficial to humankind, even if this manipulation impairs the integrity of natural systems and subverts the natural successional processes of species turnover and replacement over evolutionary time. A pivotal issue is how humankind addresses situations in which humans have exceeded natural carrying capacity. If humankind attempts to evade natural law by enabling unsustainable practices such as exponential population growth, sustainability will be a vision but not a reality.

A concomitant pivotal issue is how humankind develops the ability to assess ecological risks with enough 'lead time' to take precautionary action to avert catastrophic outcomes. Ecosystems are notoriously non-linear, chaotic, and complex, and, as a result of this predicament, they suffer from the same challenges observed in weather systems, brain physiology, or quantum mechanics. As one physicist has stated (P. Leigh, pers. comm.): 'Relativity eliminated the Newtonian illusion of absolute space and time; quantum theory eliminated the Newtonian dream of a controllable measurement process; and chaos eliminates the Laplacian fantasy of deterministic predictability.' Biologist E. O. Wilson (1998) takes the matter one step further: 'Biology is almost unimaginably more complex than physics, and the arts equivalently more complex than biology.' In a recent presentation on Policy Options for Controlling $\mathrm{CO}_{2}$, Stephen Peck (Electric Power Research Institute), a leading atmospheric economist, opened his talk by asking: 'How many of you believe we should undertake severe economic sacrifices for controlling greenhouses [gases]?' Few in the audience raised their hands. Later, Leigh (pers. comm.) conveyed to Peck that one also needs to ask how many believe that no action (currently in place) is an appropriate response to this problem. Obviously, most people believe that something needs to be done; the ques-

${ }^{1}$ Kinne, O (2002) Revisiting eco-ethics and econ-ethics. ESEP 2002:88-89, available at http://www.esep.de/articles/esep/ 2002/e23.pdf tion remains of what degree. The perception and science of risk are extremely challenging when uncertainties remain so high and complexities so compounding. The issue surrounding sustainability is often clouded with the lack of consensus regarding what to sustain; or worse, even where clarity is achieved, consensus is missing on determining sets of indicators for verifying that goals have or have not been reached. Science is essential in choosing endpoints or indicators for the latter situation, but ethics is essential for establishing goals.

The transition from unsustainable to sustainable practices will be gradual, but it must be carried out within an ethical framework so that the goals are clear and universally applicable and gross violations of ethics universally condemned. As Hillary (2000) remarks, the trade debate has been transformed into a globalization debate. However, protests at the World Trade Organization indicate that globalization has become a contentious process, especially with regard to the environmental trends associated with it. However, globalization could also be a broad cultural integration, ideally guided by ethics. Finally, nature is violent, profligate with the lives of individuals in ways that preserve the species and the system, practices infanticide, and sacrifices lives in pursuit of reproductive success. Yet humankind proposes to achieve perpetual use of the planet while maintaining a harmonious relationship with nature. Sustainability ethics must be the basis for the complex ethics necessary to make this hypothesis defensible.

An executioner is employed to kill those sentenced to death by law. Generally, law is interpreted as the laws of one species, Homo sapiens, and is usually carried out by representatives of a nation state. Before humans appeared on the planet, nature's laws were supreme. Technology and creativity have given humankind the illusion that it is the only species exempt from nature's laws; some short-term evidence supports this view, but the long-term evidence does not. Quick technological fixes may temporarily postpone a crisis, but, inevitably, the unexpected side effects may be worse than the original problem.

The framework for coping with environmental crises already exists. One only needs to substitute the term 'environmental problems' for the word 'terrorism' in American President Bush's State of the Union Address: 'This country has many challenges. We will not deny, we will not ignore, we will not pass along our problems to other Congresses, to other presidents and other generations. We will confront them with focus, clarity and courage' (Bush 2003). The growing linkages to potential human influences on the atmospheric/ocean grid via greenhouse gases are widely discussed in leading scientific journals and the mass media. How can one 
scientifically discount these concerns? American television commentator Andy Rooney's closing remarks regarding the space shuttle Columbia tragedy fit equally well when considering sustainable use of the planet: 'Rarely does man concern himself with caring about future generations, but the space program is one example where he does.' ${ }^{2}$ Clearly, sustainable use of the planet should be another.

\section{THE ECOCENTRIC SOCIAL CONTRACT}

Sustainable use of the planet is basically an ecocentric contract. Since neither future generations nor other life forms can communicate with humans presently alive as well as humans can with each other (despite isolating factors such as language), a consensus is much more difficult, arguably impossible, than in a homocentric context. The ethical responsibility of humans for the well being of other species has been discussed at some length. However, sustainability ethics has as a central component humankind's ethical responsibility for a dynamic relationship that has the potential for the co-evolution of a mutualistic relationship between humankind and the interdependent web of life. This responsibility does not preclude a satisfying relationship with individuals of other species. However, it is more difficult to achieve since an ecosystem's identity is not as apparent as the identity of an individual of another species.

Liberalism of the early 19th century recognized the self-interest of the individual as the driving force in both economics and society as a whole. Friedman (1962) postulated two primary sets of values: freedom, and values relevant to the individual in the exercise of freedom (individual ethics). The free market (pure capitalism) assumes that individuals should be allowed to pursue their economic interests freely, regardless of whether they do so in a selfish, generous, foolish, or wise way. Economic growth of this sort has taken on many of the attributes of a global ideology. It ignores or gives only lip service to the integrity of natural systems and the protection of endangered species, aesthetically pleasing vistas, wildlife preserves, nature parks, and the like. A global ethic does not mean a minimum ethic that offends no one and requires no major changes in behavior or lifestyle. A global ethic inspires behavior and practices that are sustainable and compassionate to other life forms as well as human descendants.

The planet is already in a logarithmic phase of environmental change that began in the 20th century, if not

\footnotetext{
${ }^{2 "}$ A Death in the Family" (2003) 60 Minutes. Exec. Prod. Don Hewitt. 2 February 2003. Columbia Broadcasting System, New York
}

earlier (e.g. McNeill 2000). There is too little time left for humankind to avoid a major environmental catastrophe. Abandoning political rhetoric, nationalistic posturing, and electioneering is essential at all levelslocal, national, and international. Statesmanship, guided by ethics and reason, will lead humankind from unsustainable to sustainable practices. This course will benefit all life forms, including humans, by providing a habitable planet. Sustaining, let alone raising, standards of living as presently defined is resource intensive, but could be resource friendly while increasing social capital and generally improving the quality of life if material possessions are not central to defining quality.

Nation states have had well over a century to embrace sustainable practices and have failed miserably in moving toward sustainability. Some nation states have done far better than others, but only a few. A criterion for when nation states have taken sustainability seriously is cessation of environmentally damaging federal subsidies. Despite the disproportionate influence of special interest groups upon their policies, nation states have a major role to play in the quest for sustainable use of the planet. Once their citizens make it abundantly clear that they want more positive policies (and implementation of these policies) designed to protect the environment and leave a habitable planet for future generations, the nation states should perform adequately, although some legislators will remain under the influence of special interest groups. The United Nations has already gathered much useful information needed to indicate where global policy changes are needed to achieve sustainability, but stronger support is needed from the nation states for change to become fully effective.

The probability of crossing a major ecological threshold before reaching a consensus on a global ethic already appears substantial and rapidly increasing. The environmental crisis appears to be understood by many of the world's people, but less so by its leaders. Alternatively, and most likely, it is well understood by the latter, but they are afraid it would be political suicide to bring bad news (i.e. abandoning unsustainable practices) to the general public. This situation might even be a case of co-dependency: the general public in affluent nation states are addicted to their present lifestyle and reward political leaders who encourage this addiction. The political leaders are also rewarded with campaign funds provided by special interest groups, some of which receive governmental subsidies for environmentally damaging activities.

Hausman (2000) illustrates how the government may confuse citizens with government-generated misinformation. Sagan (1993) discusses the related issue of pseudo-science. When a natural instinct for science 
and inherent curiosity about how the world works is unsatisfied, people turn to superstition and pseudoscience. Sustainable use of the planet is dependent upon literacy in science and technology, and pseudoscience and superstition will be substituted for robust science unless the latter is explained in a nonintimidating way. One could justifiably state the same idea about ethics in science and environmental politics, which is why such organizations as the EcoEthics International Union are so important. Demographic shifts are already large and increasing, but they are modest compared to the number of environmental refugees that could easily result from a modest rise in sea level (e.g. Cairns 2002).

Average citizens are becoming more concerned, but not yet alarmed, by increasing damage to the biosphere. When sufficient numbers become truly alarmed, they will decide what sort of planet they hope to leave to their descendents. Of course, citizens will be more effective in democratic parts of the world than in the non-democratic parts. Non-governmental organizations will grow rapidly and be devoted to sustainable use of the planet, eco-ethics, and the like.

Harsh penalties will emerge for those who engage in unsustainable practices. The burning ethical issue is: will humankind develop and administer the penalties or wait for nature to do so? If humankind takes the responsibility for carrying out the penalties, these will be repugnant and distasteful but, in the long run, might prevent nature's even harsher penalties. Humankind developed the unsustainable practices and is ethically responsible for replacing them with sustainable practices. Unsustainable practices will be stopped! The only question is how they will be stopped.

As Van De Veer \& Pierce (1994) note, almost all traditional moral outlooks assume that only harm or benefit to humankind is morally significant. A corollary assumption is that all other life forms, as well as nonliving material, have no value except in their utility to humankind as a means to an end. Another question is whether ecosystems, rather than the individuals who make up those ecosystems, are the real source of inherent value. Both eco-ethics and sustainability ethics assert the importance of natural systems. Both also assert that individuals whose practices impair ecosystem integrity are guilty of unethical behavior. The balance between preserving ecosystem integrity and individual freedom is very delicate.

The declarations that follow represent a preliminary attempt to determine the ethical position that will enable humankind to use Earth indefinitely, while simultaneously preserving the integrity of the ecological life support system upon which humankind is dependent.

\section{DECLARATION OF SUSTAINABILITY ETHICS}

The preliminary draft of this declaration was written in 2000 and subsequently published (Cairns 2002). After a declaration of eco-ethics ${ }^{3}$ was published, it seemed appropriate to follow it with a declaration of sustainability ethics. In order to make this declaration congruent with that of eco-ethics, significant modification of the original pledge has been necessary.

\section{Declaration}

We living representatives of humankind, in order to leave a habitable planet for our descendants and those of other species, hereby declare:

1. Humankind is a component of the interdependent web of life-if it damages the web, it damages its future.

2. Humankind cannot survive without the natural capital and ecosystem services the web of life (the biosphere) provides and will not use for itself the resources needed to maintain the web's integrity and function.

3. Humankind will follow nature's model, which is based upon systematic recycling and reuse, and will not produce either products or wastes that are harmful rather than beneficial to natural systems.

4. Humankind will use technology and creativity to protect nature's resource reserves rather than to make them more readily available on demand.

5. Humankind recognizes that no form of exponential growth on a finite planet is sustainable. Exponential economic growth may postpone the consequences of violating nature's laws but also increases the magnitude of the penalties for exceeding the planet's carrying capacity.

6. Humankind pledges to limit its acquisition of material goods to what Earth can afford rather than what humans can afford.

7. Humankind proclaims that, henceforth, any degradation of Earth's biospheric life support system will be restored to predisturbance condition whenever possible and repaired when restoration is not a viable option.

8. Humankind pledges to reject a lifestyle that drives other species to extinction and to esteem other life forms.

9. Humankind pledges to take precautionary actions when adverse consequences to the biosphere would

\footnotetext{
${ }^{3}$ Cairns J Jr (2002) A declaration of eco-ethics. ESEP 2002: 79-81, available at http://www.esep.de/articles/esep/2002/ E21.pdf
} 
occur from activities of the species; consequences might be severe, even in the face of significant uncertainty.

10. When nation states violate the laws of nature by continuing unsustainable practices, humankind will feel compassion for the suffering but will recognize that the only way to ensure respect for nature's laws is to let the guilty suffer the consequences as they do for violations of human law. Arguably, this will be the most difficult part of the declaration to adhere to, but failure to do so will leave a less habitable planet for future generations.

\section{ILLUSTRATIVE SUSTAINABILITY ETHICS FOR NATION STATES}

1. Cease all environmentally damaging subsidies. (This pledge will be particularly difficult to initiate at both the corporate and individual citizen level. The corporate level will be difficult because of the wellfinanced special interest groups. The individual level will be difficult because of the perceived encroachment upon individual rights. For example, the human population must eventually stabilize on a finite planet. Many individuals will resist population control unless everyone participates (for example, an income tax deduction that does not increase for more than two children). The world's population will stabilize; the only question is will humankind achieve it before nature does? Sustainability is, arguably, the most important nation state security issue.)

2. Develop and implement an energy policy that is not based on fossil fuels. (This pledge, too, is inevitable, so it might as well begin now.)

3. Tax the inefficient use of fossil fuels in vehicles, industry, and housing during the transition to renewable energy.

4. Protect both natural capital and ecosystem services and encourage accumulation of natural capital by means of ecosystem restoration and repair.

5. Develop and implement bioregional plans that foster sustainable use of both private and government land and property.

6. Develop and implement sustainable policies that protect the integrity of the hydrologic cycle and water quality.

7. Ensure protection and restoration of wildlands so there will be ecosystems on which restoration and management models can be based.

8. Develop and implement policies that reduce biological impoverishment (species extinction) and encourage maintenance of biodiversity.

9. Require that industrial, municipal, and household wastes be suitable for re-incorporation into natural systems in a beneficial way.

10. Prohibit the production of hazardous wastes whose long-term half-life requires isolation from natural systems and humankind (i.e. nuclear wastes and persistent toxic chemicals).

\section{CONCLUSIONS}

Humankind is carrying out an experiment at spatial and temporal scales unprecedented in human history. Worse yet, most people are unaware that humanity's present lifestyle is unsustainable. Most humans see the world at a local or regional scale, but must now extrapolate at scales essential to sustainable use of the planet. Personal experience is inadequate for viewing the entire range of phenomena essential to the quest for sustainability. Much of the necessary information must come from scientists and other professionals, but the details will require a higher and broader literacy level than most humans possess. As a consequence, faith is essential in both the information and the people who generated it. Trust develops when individuals and nation states share a common ground. The process of globalization has made Earth a common ground to an extent unprecedented in human history. As a species, humankind has evolved from small tribal groups with a small common ground to nation states with a much larger common ground. Much of humankind has not yet adapted to this larger common ground, as ethnic wars in other countries indicate. Now, exponential growth of the human population has, in a blink of an eye in evolutionary time, thrust humankind into a global community that concomitantly has a rapidly deteriorating environment and the depletion of natural capital. Regrettably, the conditions of an increasingly impersonal world, the result of living in enormous groups (almost nation cities), have decreased any feeling of connectedness at a time when sustainable use of the planet requires it most. Sustainability ethics, the ethics of a sustainable world, appears to be the most promising means of reestablishing the feeling of connectedness, before a global catastrophe results from unsustainable practices. Ethics offers the prospect of transcending the many isolating mechanisms that have resulted in culture wars, which will almost certainly be exacerbated by resource wars.

It is imperative that humankind live sustainably and in harmony with other life forms. Failure to adapt to new conditions resulted in extinction of species long before humans appeared on the planet. The human race cannot plea bargain with nature. It can develop, however, an ethic compatible with the desire for a sustainable world. 
Acknowledgements. I am indebted to K. Cairns for transcribing the handwritten draft of this manuscript and D. Donald for her usual excellent editorial assistance on all drafts. P. Leigh provided useful comments on the second draft. The Cairns Foundation paid for processing costs.

\section{LITERATURE CITED}

Bush, GW (2003) Text: Bush's 2003 state of the Union address. The Washington Post, 28 Jan:A-10

Cairns J Jr (2002) Making peace with the biosphere. In: Triphathi G, Tripathi YC (eds) Bioresource and environment. Campus Books, New Delhi, India

Friedman M (1962) Capitalism and freedom. University of Chicago Press, Chicago, IL

Hausman C (2000) Lies we live by: defeating double-talk and

Editorial responsibility: Mary Batson (Managing Editor),

Oldendorf/Luhe, Germany deception in advertising, politics, and the media. Routledge, New York

Hillary F (2000) Vanishing borders: protecting the planet in the age of globalization. WW Norton, New York

Kinne O (2003) Eco-ethics further developed text: 01.05.2002. EEIU Brochure, Inter-Research, Oldendorf/Luhe

McNeill JR (2000) Something new under the sun: an environmental history of the twentieth century world. WW Norton, New York

Sagan C (1993) Science and pseudo-science. In: Jarmul D (ed) Headline news, science views I. National Academy Press, Washington, DC

Van De Veer D, Pierce C (1994) The environmental ethics and policy book. Wadsworth Publishing Company, Belmont, CA

Wilson EO (1998) Consilience: the unity of knowledge. Alfred A. Knopf, New York

Wilson EO (2002) The future of life. Random House, New York

Submitted: March 3, 2003; Accepted: May 14, 2003

Proofs received from author(s): May 21, 2003

Published on the web: May 26, 2003 